\title{
Migration rules of PHC in bottom waters in Jiaozhou Bay Yu Chen ${ }^{1}$, Danfeng Yang ${ }^{2}$, Xiancheng $\mathrm{Qu}^{3}$, Quanhong $\mathrm{Yu}^{1}$ and Dongfang Yang $3,4, a$ \\ ${ }^{1}$ College of Information, Shanghai Ocean University, Shanghai 201306, China; \\ ${ }^{2}$ College of Information Science and Engineering, Fudan University, Shanghai 200433, China; \\ ${ }^{3}$ College of Life Science, Shanghai Ocean University, Shanghai, 201306, China; \\ ${ }^{4}$ North China Sea Environmental Monitoring Center, SOA, Qingdao 266033, China. \\ adfyang_dfyang@126.com
}

Keywords: PHC; Distribution; Water quality; Migration rules; Jiaozhou Bay

\begin{abstract}
Based on investigation data on petroleum hydrocarbon (PHC) in April, August and November 1981 in bottom waters in Jiaozhou Bay, we analyzed the content and distribution of PHC. Results showed that PHC contents in April, August and November 1981 in bottom waters were 0.028-0.123 $\mathrm{mg} \mathrm{L}^{-1}$ and were meeting Grade II $\left(0.05 \mathrm{mg} \mathrm{L}^{-1}\right)$ and III $\left(0.30 \mathrm{mg} \mathrm{L}^{-1}\right)$ in National Sea Water Quality Standard (GB 3097-1997). PHC contents were decreasing from the inside of the bay mouth to the outside of the bay mouth in April and August, yet were reverse in November. We found the migration rules of PHC in bottom waters in marine bay, that were the substances could be generated from both the bay and the open waters by means of vertical water's effect, and the PHC contents were diffusing from the bay mouth no matter from the bay of the open waters.
\end{abstract}

\section{Introduction}

PHC is the blood of industry, and is playing an important role in the development of economic sociology. The development of Chinese economic is strongly depending on the petroleum consumption. Hence, the PHC pollution has also been one of the critical environmental problems, including the water quality of marine environment [1-5]. The excessive PHC in marine waters could migrate to sea bottom since the sea bottom is the sink of various pollutants. The research on the contents, pollution levels and migration rules of PHC in marine bay was essential to protect the marine environment. This paper analyzed the content and distribution of PHC based on investigation dada in 1981 in bottom waters in Jiaozhou Bay, and provided basis for the research on the existence and migration of PHC in marine bay.

\section{Material and method}

Jiaozhou Bay $\left(35^{\circ} 55^{\prime}-36^{\circ} 18^{\prime} \mathrm{N}, 120^{\circ} 04^{\prime}-120^{\circ} 23^{\prime} \mathrm{E}\right)$ is a semi-closed bay located in the south of Shandong Province, eastern China (Fig. 1). The total area and bay mouth depth $446 \mathrm{~km}^{2}$ and $3 \mathrm{~km}$, respectively. The bay has more than ten inflow rivers, including Haibo Rriver, Licun Rriver and Loushan Rriver etc., all of which have seasonal features [6-7].

The data was provided by North China Sea Environmental Monitoring Center. The survey was conducted in April, August and November 1981 (Fig. 1). The sampling sites in April and August were A1, A2, A3, A4, A5, A6, A7, A8, B5 and D5 (Fig. 1), while in November were H34, H35, H36, and H37 (Fig. 2). PHC in bottom waters was sampled and monitored follow by National Specification for Marine Monitoring [8]. 


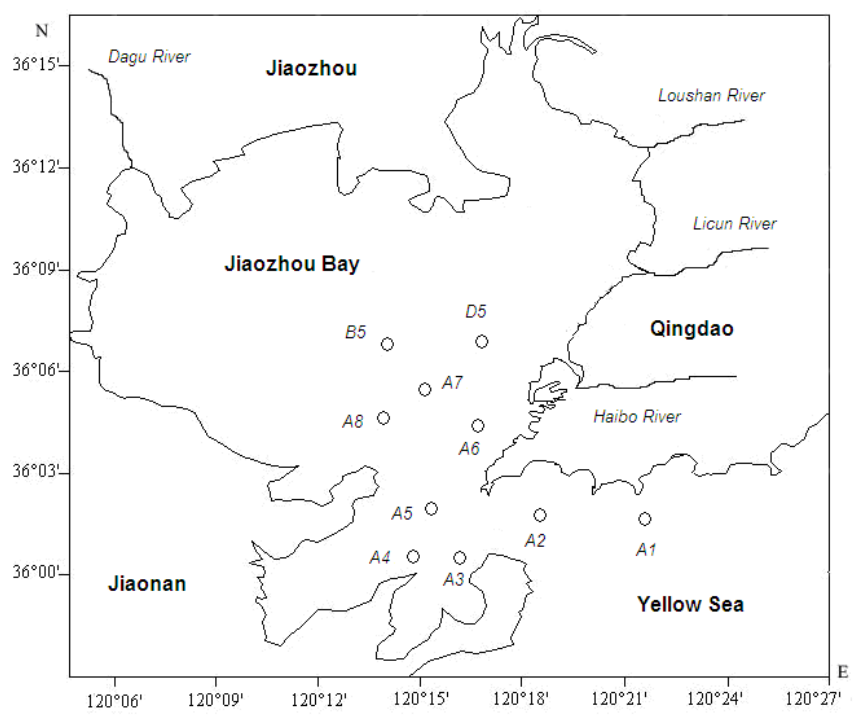

Fig.1 Investigation A-D-sites in Jiaozhou Bay

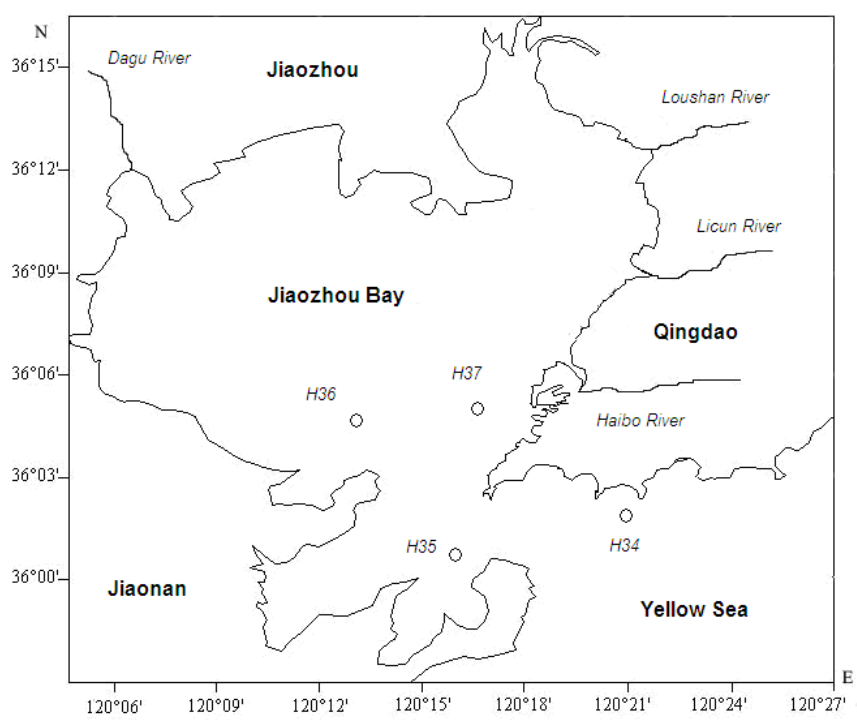

Fig.2 Investigation H-sites in Jiaozhou Bay

\section{Results and discussion}

Contents and pollution levels of PHC. The contents of PHC in April, August and November in bottom waters in Jiaozhou Bay were 0.031-0.123 $\mathrm{mg} \mathrm{L}^{-1}, 0.028-0.056 \mathrm{mg} \mathrm{L}^{-1}$ and 0.038-0.100 $\mathrm{mg} \mathrm{L}^{-1}$, respectively (Table 1). In April, PHC contents in Site D5 and B5 in the center of the bay were higher than $0.05 \mathrm{mg} \mathrm{L}^{-1}$, as well as in Site A2 in the outside of the bay mouth, and were belong to Grade III. For the other sampling sites, PHC contents were Grade II. PHC contents in August were lower than in April, PHC contents in Site A6 in the inside of the bay mouth were higher than $0.05 \mathrm{mg} \mathrm{L}^{-1}$, and were belong to Grade III, while for the other sampling sites, PHC contents were Grade II. PHC contents in November were increasing, PHC contents in the bay mouth and the outside of the bay mouth were belong to Grade III, while for the other sampling sites were Grade II. The major pollution sources of PHC in Jiaozhou Bay were overland runoff and stream flow discharge. Once PHC was transported to the bay, PHC was originally arrived at the surface waters, and then was transported through the waters, and finally was settled in the sea bottom. By means of the vertical water's effect, PHC contents in Jiaozhou Bay were $0.028-0.123 \mathrm{mg} \mathrm{L}^{-1}$, and were belong to Grand II and III. In generally, Jiaozhou Bay waters were slightly polluted by PHC in 1981. 
Table1 Pollution level of PHC in bottom waters in Jiaozhou Bay in April, August and November 1981

\begin{tabular}{|c|c|c|c|}
\hline Month & April & August & November \\
\hline Content/mg L ${ }^{-1}$ & $0.031-0.123$ & $0.028-0.056$ & $0.038-0.100$ \\
\hline Water quality grade & II and III & II and III & II and III \\
\hline
\end{tabular}

Horizontal distributions and migration rules of PHC. In April, there was a high value $(0.123$ $\mathrm{mg} \mathrm{L}^{-1}$ ) in Site D5 in the center of the bay, and there were a series of semi-concentric circles, which were decreasing from the high value center to the bay mouth $\left(0.031 \mathrm{mg} \mathrm{L}^{-1}\right)$ (Fig. 3). In August, there was a high value $\left(0.056 \mathrm{mg} \mathrm{L}^{-1}\right)$ in Site A6 in the inside of the bay mouth, and there were a series of semi-concentric circles, which were decreasing from the high value center to the outside of the bay mouth $\left(0.028 \mathrm{mg} \mathrm{L}^{-1}\right)$ (Fig. 4). In November, there was a high value $\left(0.100 \mathrm{mg} \mathrm{L}^{-1}\right)$ in Site H34 in the outside of the bay mouth, and there were a series of parallel lines, which were decreasing from the high value center to the inside of the bay mouth $\left(0.038 \mathrm{mg} \mathrm{L}^{-1}\right)$ (Fig. 5). In generally, PHC contents were decreasing from the inside of the bay mouth to the outside of the bay mouth in April and August, yet were reverse in November. The contents of the substances were decreasing continuously from the inside of the bay to the open waters along with the water exchange of the bay and the open waters, and were decreasing continuously from the open waters to the inside bay [10]. PHC contents in April and August were decreasing from the inside of the bay to the open waters, indicated that the high content PHC were from the inside of the bay, and were diffusing from the bay to the open waters. PHC contents in November were decreasing from the open water to the inside of the bay, indicated that high content PHC were from the open waters, and were diffusing from the open waters to the inside of the bay. In generally, we proposed that PHC could be generated from both open waters and the inside of the bay, and the high content PHC could be diffusing from the inside of the bay to the open waters, as well as from open waters to the inside of the bay, which were the migration rules of PHC in the bay by means of vertical water's effect.

\section{Conclusion}

By means of the vertical water's effect, PHC contents in Jiaozhou Bay were 0.028-0.123 mg L ${ }^{-1}$, and were belong to Grand II and III. In generally, Jiaozhou Bay waters were slightly polluted by PHC in 1981. PHC contents were decreasing from the inside of the bay mouth to the outside of the bay mouth in April and August, yet were reverse in November. PHC could be generated from both open waters and the inside of the bay, and the high content PHC could be diffusing from the inside of the bay to the open waters, as well as from open waters to the inside of the bay, which were the migration rules of PHC in the bay by means of vertical water's effect.

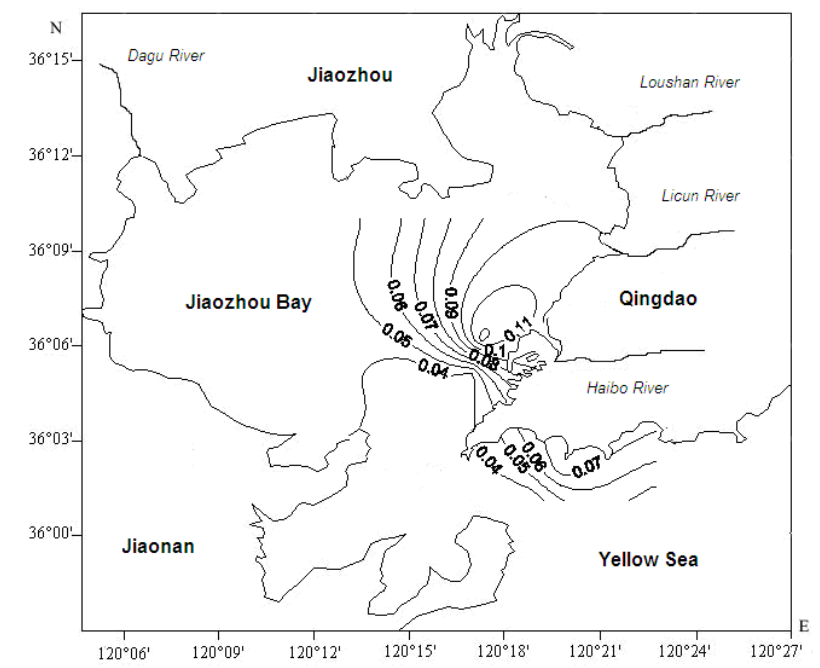

Fig. 3 Horizontal distributions of PHC in bottom waters of Jiaozhou Bay in April 1981 


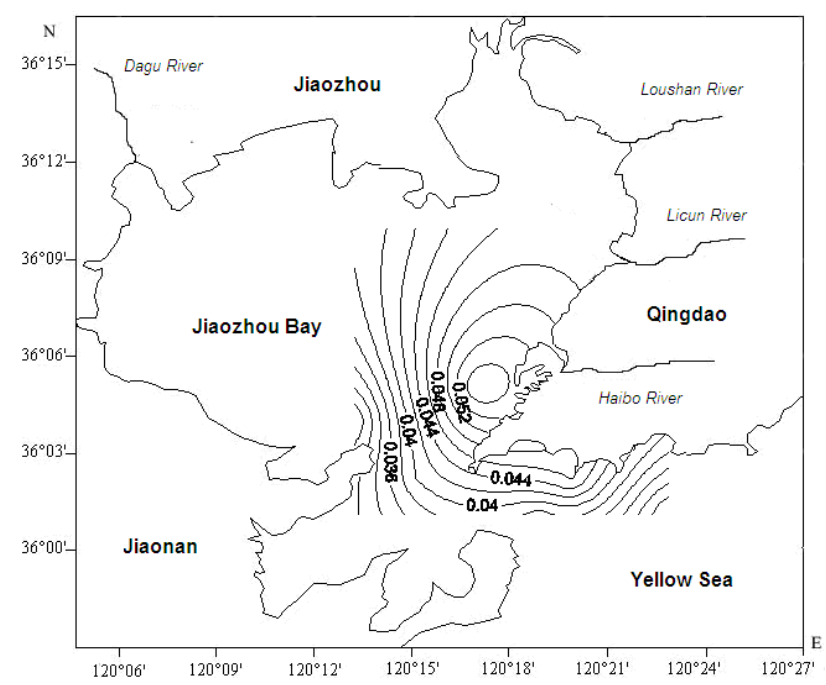

Fig. 4 Horizontal distributions of PHC in bottom waters of Jiaozhou Bay in August 1981

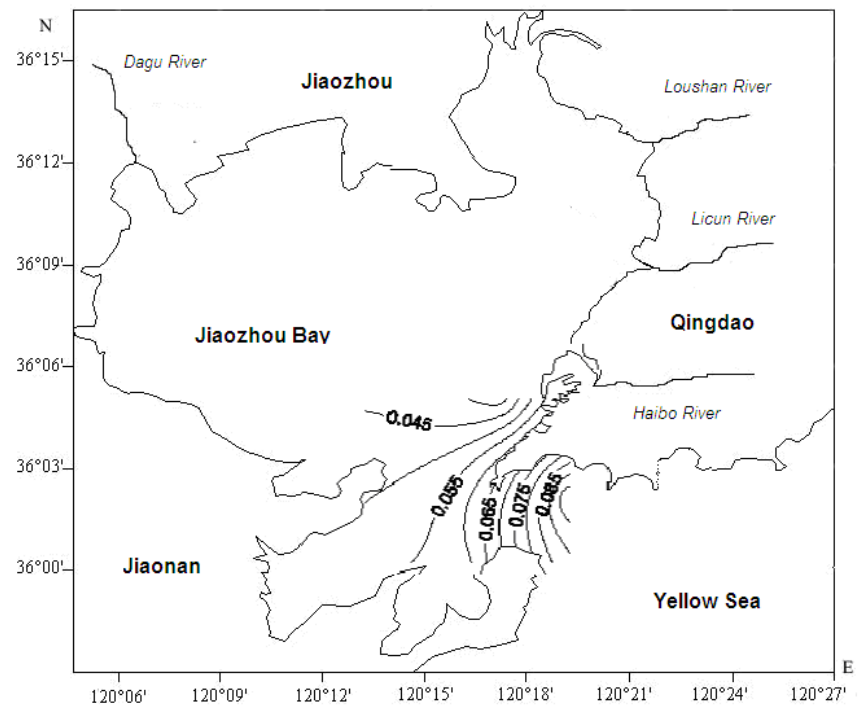

Fig. 5 Horizontal distributions of PHC in bottom waters of Jiaozhou Bay in November 1981

\section{Acknowledgement}

This research was sponsored by Doctoral Degree Construction Library of Guizhou Nationalities University, Education Ministry's New Century Excellent Talents Supporting Plan (NCET-12-0659), the China National Natural Science Foundation (31560107), Major Project of Science and Technology of Guizhou Provincial ([2004]6007-01), Guizhou R\&D Program for Social Development ([2014] 3036) and Research Projects of Guizhou Nationalities University ([2014]02), Research Projects of Guizhou Province Ministry of Education (KY [2014] 266), Research Projects of Guizhou Province Ministry of Science and Technology (LH [2014] 7376).

\section{References}

[1] Yang DF, Zhang YC, Zou J, et al.: Open Journal of Marine Science, vol. 2 (2011), p. 108-112

[2] Dongfang Yang, Peiyan Sun, Chen Chen, Hongyan Bai and Qing Zhou: Coastal Engineering, Vol. 32 (2013), p. 60- 72. (in Chinese)

[3] Yang DF, Sun PY, Ju L, et al.: Proceedings of the 2015 international symposium on computers and informatics, vol, (2015), p. 2647-2654.

[4] Yang DF, Wang FY, Zhu SX, et al.: Proceedings of the 2015 international symposium on computers and informatics, Vol. (2015), p. 2661-2666. 
[5] Yang DF, Wu FYm He HZ, et al.: Proceedings of the 2015 international symposium on computers and informatics, Vol. (2015), p. 2647-2654.

[6] Yang DF, Chen Y, Gao ZH, et al.: Chinese Journal of OceanoLogy and LimnoLogy, Vol. 23(2005), p. 72-90.

[7] Yang DF, Wang F, Gao ZH, et al. Marine Science, Vol. 28 (2004), p. 71-74. (in Chinese)

[8] China's State Oceanic Administration: The specification for marine monitoring (Ocean Press, Beijiang 1991), p.1-300. (in Chinese)

[9] Yang DF, Miao ZQ, Xu HZ, et al.: Proceedings of the 2015 international symposium on computers and informatics, Vol. 2015, p. 2655-2660.

[10]Yang DF, Miao ZQ, Xu HZ, et al.: Marine Environmental Science, Vol, 32 (2013), p. 373-380. (in Chinese) 